\title{
Properties of Agarose-Bound Soya-Bean Lipoxygenase
}

\author{
By S. Grossman, ${ }^{*}$ M. Trop, ${ }^{*}$ P. Budowski, $\dagger$ M. PerL* and A. Pinsky* \\ *Department of Life Sciences, Bar-Ilan University, Ramat-Gan, Israel, and \\ $\dagger$ Faculty of Agriculture, The Hebrew University of Jerusalem, Rehovot, Israel
}

(Received 24 February 1972)

Studies on lipoxygenase (EC 1.13.1.13) usually involve aqueous solutions of the enzyme. Recent techniques of enzyme insolubilization (Silman \& Katchalsky, 1966) do not appear to have been applied to lipoxygenase. The present paper describes some properties of an insoluble lipoxygenase preparation obtained by binding the enzyme to agarose.

Soya-bean lipoxygenase (Fluka A.G., Buchs, Switzerland) was purified by chromatography on CM-cellulose (Grossman et al., 1969). The eluate obtained with $0.1 \mathrm{M}$-sodium acetate buffer, pH5.5, was dialysed against water and freeze-dried. Insolubilization was achieved by making the purified enzyme react with CNBr-treated agarose (Axen et al., 1967; Cuatrecasas et al., 1968). The insoluble product was washed with $0.1 \mathrm{M}-\mathrm{NaHCO}_{3}$ to remove any remaining soluble lipoxygenase, and with water to remove the $\mathrm{NaHCO}_{3}$. Preparations were obtained containing $1-12 \mathrm{mg}$ of protein/g of agarose. The products retained their activity for at least 1 month when stored wet at room temperature.

Activity was determined by polarographic measurement of oxygen uptake by linoleate, as described for soluble lipoxygenase (Grossman et al., 1969). Additional criteria used were diene conjugation of linoleate and bleaching of a carotene-linoleate solution. These techniques were applied by forming the agarose-lipoxygenase gel into a column $3 \mathrm{~cm}$ high and $1 \mathrm{~cm}$ in diameter and allowing $5-10 \mathrm{ml}$ of linoleate solution (7.5 mM) (Grossman et al., 1969) or $20 \mathrm{ml}$ of linoleate $(750 \mu \mathrm{g} / \mathrm{ml})-\beta$-carotene solution $(10 \mu \mathrm{g} / \mathrm{ml})$ (Ben Aziz et al., 1971) to percolate through the column over a time-interval of 7-10 min. Conjugated dienes in the effluent were measured spectrophotometrically at $234 \mathrm{~nm}$ (Ben Aziz et al., 1970) and the carotene remaining in the effluent was determined spectrophotometrically at $460 \mathrm{~nm}$ (Ben Aziz et al., 1971).

Both soluble and agarose-bound forms of the enzyme rapidly oxidized linoleate, whereas they were completely inactive towards oleate. The specific activities of the soluble and insoluble preparations were 200 and $190 \mu \mathrm{l}$ of $\mathrm{O}_{2} / \mathrm{min}$ per $\mathrm{mg}$ of protein respectively. A similar substrate specificity was observed when the substrate solution was percolated through agarose-bound lipoxygenase: a pronounced diene peak was formed from linoleate, whereas no peak appeared with oleate as a substrate.

Percolation of an aqueous carotene-linoleate solution through a column of agarose-bound lipoxygenase caused the bleaching of $70 \%$ of the carotene. No autoxidation of carotene was observed during the test period, and when linoleic acid was omitted from the test solution the entire amount of carotene was recovered in the effluent.

The pH optima for the soluble and insoluble preparations were 7.0 and 8.0 respectively. The agarose-bound enzyme appeared to exhibit little activity below pH6.5, whereas the soluble lipoxygenase was still markedly active at pH6.0.

Nordihydroguaiaretic acid [2,3-dimethyl-1,4-bis(3',4'-dihydroxyphenyl)butane], which is known as an effective antioxidant and inhibitor of lipoxygenase, completely inhibited both soluble and insoluble lipoxygenase in the linoleate-oxidizing system, at a concentration of $0.1 \mathrm{mM}$. At a concentration of $35 \mu \mathrm{M}$ nordihydroguaiaretic acid caused 62 and $84 \%$ inhibition of soluble and insoluble lipoxygenase respectively.

Michaelis constants were determined from Lineweaver-Burk plots over the range $1-0.01 \mathrm{~mm}$-linoleate. $K_{m}$ values were $1.8 \times 10^{-4} \mathrm{M}$ and $3.0 \times 10^{-4} \mathrm{M}$ for the soluble and insoluble enzyme respectively.

The effluent obtained when an aqueous solution of linoleate was percolated through agarose-bound lipoxygenase exhibited a pronounced peak close to $234 \mathrm{~nm}$ characteristic of a conjugated diene hydroperoxide. A similar effect was observed for agarosebound haemoglobin prepared in the same fashion as insoluble lipoxygenase. Haemoproteins, like lipoxygenase, are known to catalyse the peroxidation of linoleate, but the primary reaction catalysed by haemoproteins is believed to be the homolytic scission of preformed hydroperoxide (Tappel, 1961), a process resulting in the setting up of radicalpropagated autoxidation chains. When pre-oxidized linoleate was percolated through agarose-bound haemoglobin, the diene peak originally present disappeared, to be replaced by a maximum at $222 \mathrm{~nm}$ and several minor peaks between 250 and $300 \mathrm{~nm}$. Insoluble lipoxygenase, on the other hand, did not alter the diene absorption spectrum of pre-oxidized linoleate. The destruction of conjugated diene hydroperoxide in the presence of haemoglobin is similar to the effect of a lipohydroperoxidase present in lucerne (Medicago sativa) (Gardner, 1965) and strengthens the assumption that haemoproteins act primarily on hydroperoxides. 
Table 1. Formation of substrate-enzyme complex with two preparations of agarose-bound lipoxygenase

Agarose-bound lipoxygenase was first washed anaerobically with deaerated $0.2 \mathrm{M}$-sodium phosphate buffer, $\mathrm{pH} 7.5$, at $25^{\circ} \mathrm{C}$. Linoleate solution $(5 \mathrm{ml})$ (Grossman et al., 1969), labelled with $2.7 \times 10^{6}$ c.p.m. of [U- ${ }^{3} \mathrm{H}$ ]linoleate $(4.3 \mathrm{Ci} / \mathrm{mmol}$; Israel Nuclear Research Center, The Negev, Israel), was then added and stirred anaerobically with the enzyme preparation for $10 \mathrm{~min}$. After removal of excess of substrate by exhaustive washing with deaerated buffer, the enzyme-substrate complex was decomposed by stirring with the phosphate buffer for $1 \mathrm{~h}$ under air, and this was followed by washing with the buffer until no conjugated dienes or radioactivity could be detected in the washings. Molar amounts were computed from the molar extinction coefficient of 25600 for linoleic acid hydroperoxide (Holman, 1947) and the molecular weight of 100000 for soya-bean lipoxygenase (Tappel, 1963). Protein content was determined as the difference between the amount of protein added and that recovered from the supernatants after completion of the binding reaction, the actual determination being by the method of Lowry et al. (1951). Radioactivity was measured by counting that of $1.0 \mathrm{ml}$ of effluent in $10 \mathrm{ml}$ of Bray's (1960) solution in a Packard model 3003 scintillation counter, all values being corrected for internal quenching.

$\begin{array}{cccc}\text { Enzyme } & \begin{array}{c}\text { Protein content } \\ \text { preparation }\end{array} & \overbrace{\text { (mg/g of agarose) }} & \begin{array}{c}\text { Rabstrate-enzyme molar ratios } \\ \text { computed from measurement of }\end{array} \\ \text { A } & 3.5 & 1.7 & \text { Conjugated dienes } \\ \text { B } & 11.2 & 1.6 & 2.1 \\ & & & 1.7\end{array}$

The above results illustrate the similarity between soluble and insoluble lipoxygenase, as well as the different actions of lipoxygenase and haemoglobin on pre-oxidized linoleate. The insoluble lipoxygenase also permits an elegant demonstration of the existence of an enzyme-substrate complex. It was found that insoluble lipoxygenase was able to bind linoleic acid to form a complex, stable under anaerobic conditions. When this complex was subsequently brought in contact with air, conjugated diene hydroperoxide was formed and released into solution, and this could be determined both by spectrophotometry and by the amount of radioactivity released when labelled linoleic acid was used. The results of a typical experiment with two different preparations are presented in Table 1. It was found that $1.6-2.1 \mathrm{~mol}$ of oxidized linoleate was released from $1 \mathrm{~mol}$ of enzyme, with reasonably good agreement between the two assay techniques. In the present experiments a large excess of substrate was present: the molar ratio of substrate to enzyme, as measured by the amount of reaction product released, was not significantly affected by increasing the amount of enzyme introduced into the reaction system, indicating that the insoluble enzyme was saturated with substrate.

Attempts to study the enzyme-substrate complex by the technique of equilibrium dialysis were unsuccessful because it was not possible to prevent adsorption of linoleic acid on the dialysis membrane.

Part of this work was done with the aid of Grant no. 161-81-05-5 from the Bar-Ilan University Research Fund.

Axen, R., Porath, J. \& Ernback, S. (1967) Nature (London) 214, 1302

Ben Aziz, A., Grossman, S., Ascarelli, I. \& Budowski, P. (1970) Anal. Biochem. 34, 88

Ben Aziz, A., Grossman, S., Ascarelli, I. \& Budowski, P. (1971) Phytochemistry 10, 1445

Bray, G. A. (1960) Anal. Biochem. 1, 279

Cuatrecasas, P., Wilchek, M. \& Anfinsen, C. B. (1968) Proc. Nat. Acad. Sci. U.S. 61, 636

Gardner, H. W. (1965) Ph.D. Thesis, Pennsylvania State University

Grossman, S., Ben Aziz, A., Budowski, P., Ascarelli, I., Gertler, A., Birk, Y. \& Bondi, A. (1969) Phytochemistry 8, 2287

Holman, R. T. (1947) Arch. Biochem. 15, 403

Lowry, O. H., Rosebrough, N. J., Farr, A. L. \& Randall, R. J. (1951) J. Biol. Chem. 193, 265

Silman, I. H. \& Katchalski, E. (1966) Annu. Rev. Biochem. 35, 873

Tappel, A. L. (1961) in Autoxidation and Antioxidants (Lundberg, W. O., ed.), vol. 1, p. 325, Interscience, New York

Tappel, A. L. (1963) Enzymes, 2nd. edn., 8, 275 